\title{
Development and Deployment of Retrofit PolarisQ Ion Trap Mass Spectrometer for Isotope Ratio Measurements
}

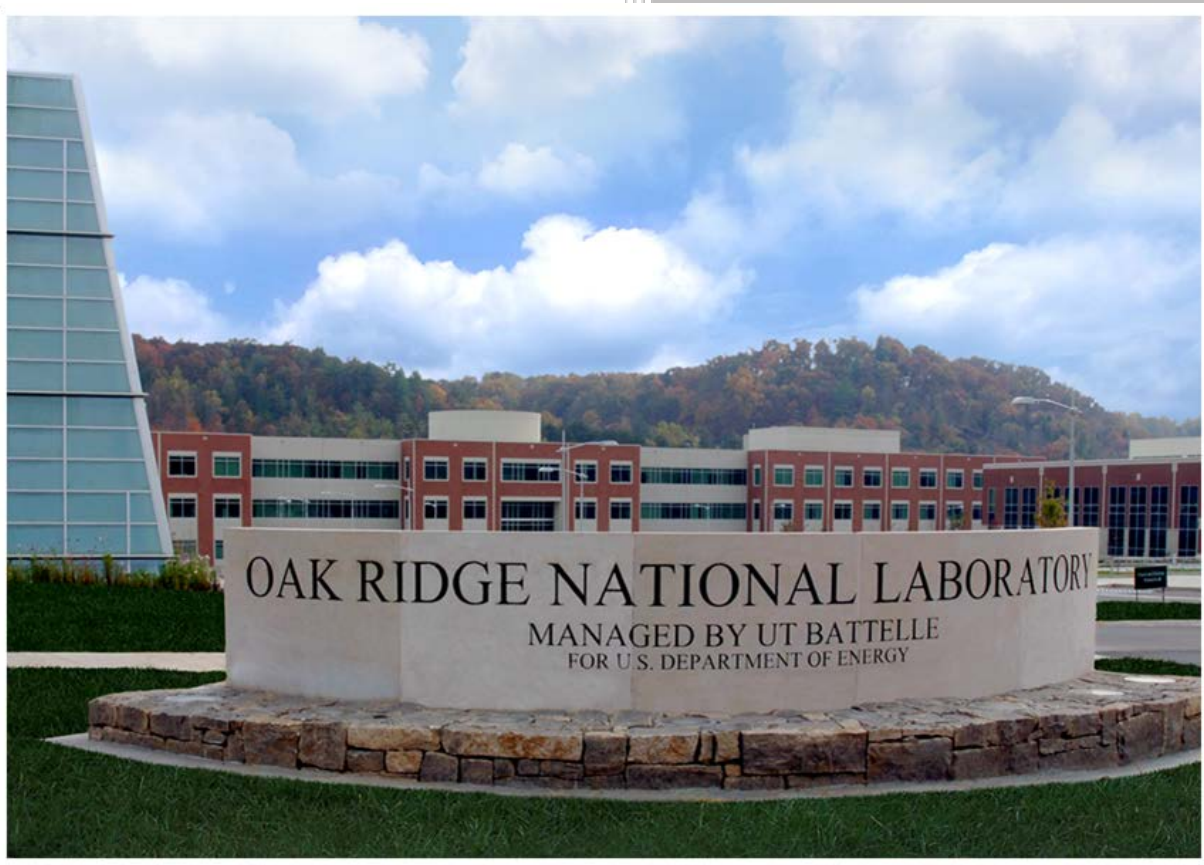

Approved for public release. Distribution is unlimited.
Cyril V. Thompson William B. Whitten

November 2015 


\title{
DOCUMENT AVAILABILITY
}

Reports produced after January 1, 1996, are generally available free via US Department of Energy (DOE) SciTech Connect.

\section{Website http://www.osti.gov/scitech/}

Reports produced before January 1, 1996, may be purchased by members of the public from the following source:

\author{
National Technical Information Service \\ 5285 Port Royal Road \\ Springfield, VA 22161 \\ Telephone 703-605-6000 (1-800-553-6847) \\ TDD 703-487-4639 \\ Fax 703-605-6900 \\ E-mail info@ntis.gov \\ Website http://www.ntis.gov/help/ordermethods.aspx
}

Reports are available to DOE employees, DOE contractors, Energy Technology Data Exchange representatives, and International Nuclear Information System representatives from the following source:

Office of Scientific and Technical Information

PO Box 62

Oak Ridge, TN 37831

Telephone 865-576-8401

Fax 865-576-5728

E-mail reports@osti.gov

Website http://www.osti.gov/contact.html

This report was prepared as an account of work sponsored by an agency of the United States Government. Neither the United States Government nor any agency thereof, nor any of their employees, makes any warranty, express or implied, or assumes any legal liability or responsibility for the accuracy, completeness, or usefulness of any information, apparatus, product, or process disclosed, or represents that its use would not infringe privately owned rights. Reference herein to any specific commercial product, process, or service by trade name, trademark, manufacturer, or otherwise, does not necessarily constitute or imply its endorsement, recommendation, or favoring by the United States Government or any agency thereof. The views and opinions of authors expressed herein do not necessarily state or reflect those of the United States Government or any agency thereof. 
Chemical Sciences Division

\title{
Development and Deployment of Retrofit PolarisQ Ion Trap Mass Spectrometer for Isotope Ratio Measurements
}

\author{
Cyril V. Thompson \\ William B. Whitten
}

Date Published: November 2015

Prepared by

OAK RIDGE NATIONAL LABORATORY

Oak Ridge, TN 37831-6283

managed by

UT-BATTELLE, LLC

for the

US DEPARTMENT OF ENERGY

under contract DE-AC05-00OR22725 
THIS PAGE LEFT BLANK INTENTIONALLY 
This report describes Oak Ridge National Laboratory's (ORNL) FY15 progress in support of National Nuclear Security Administration's (NNSA) Portable Mass Spectrometer project. A retrofit PolarisQ ion trap mass spectrometer (RPMS) has been assembled from components of two PolarisQ ion trap mass spectrometers used in previous isotope ratio programs (Figure 1). The retrofit mass spectrometer includes a custom Hastelloy vacuum chamber which is about $1 / 4$ the size of the standard aluminum vacuum chamber and reduces the instrument weight from the original by nine pounds. In addition, the new vacuum chamber can be independently heated to reduce impurities such as water, which reacts with $\mathrm{UF}_{6}$ to produce HF in the vacuum chamber. The analyzer and all components requiring service are mounted on the chamber lid (Figure 2), facilitating quick and easy replacement of consumable components such as the filament and electron multiplier.

Figure 1. RPMS Deployed at ORNL Test Loop

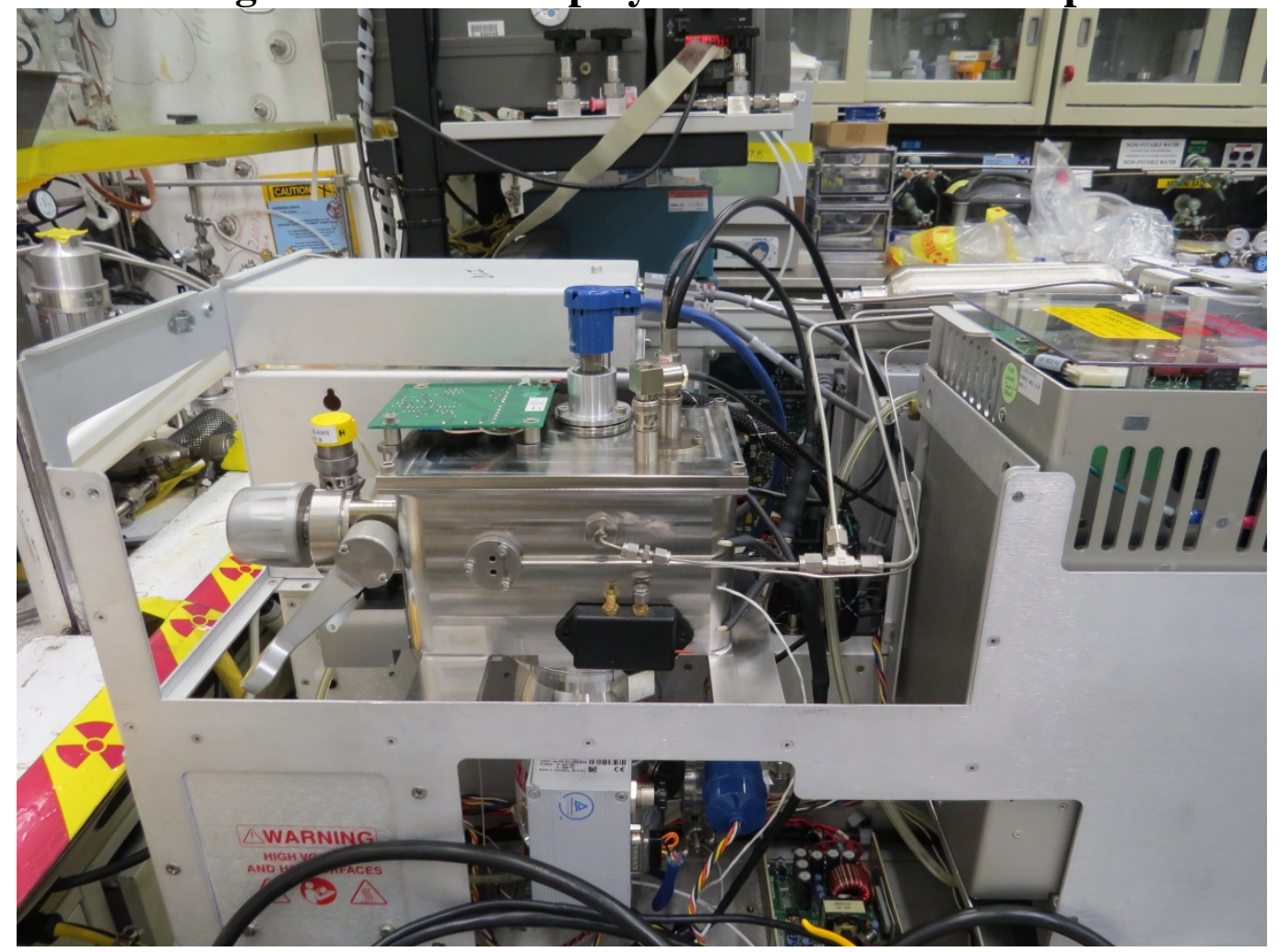




\section{Figure 2. RPMS Analyzer Assembly}

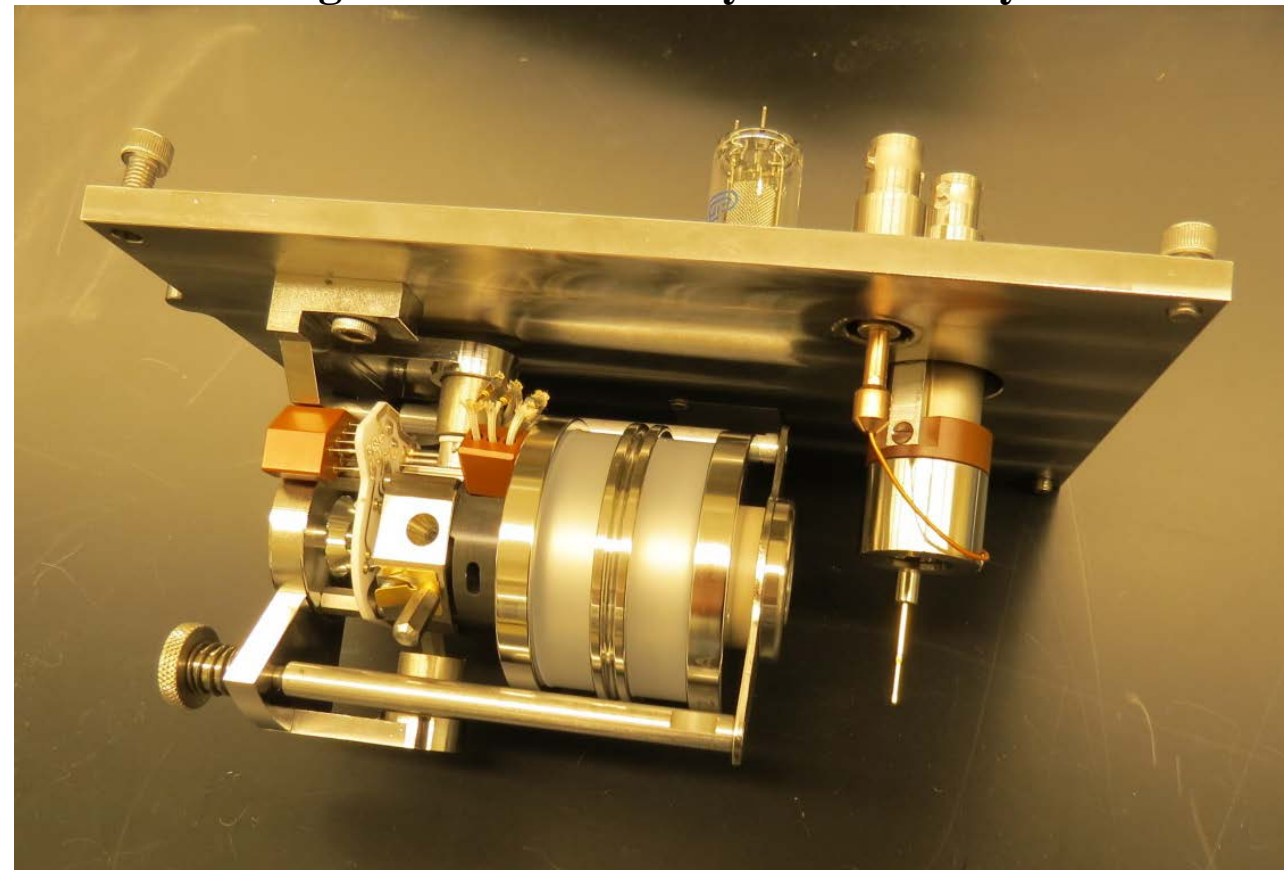

The RPMS was assembled and tested with perfluorotributylamine (PFTBA), a standard calibration compound often used with mass spectrometers. In initial tests, the instrument performed well in electron impact (EI) positive ion mode. This is the standard mode of operation used for instrument tuning and calibration.

After confirmation of instrument performance, the RPMS was moved to the ORNL Test Loop and used for analysis of $U_{6}$ to determine its performance in assessment of isotope ratios. Both ${ }^{238} U F_{5}$ and ${ }^{238} U_{6}$ were observed in the tests. However, varying amounts of ${ }^{235} U_{5}$ and almost no ${ }^{235} U F_{6}$ were detected. As can be seen in the mass spectra in Figure 3, the standard PolarisQ spectrum has peaks with leading and trailing shoulders (gentle curvature at the base of the peaks), but the spectrum from the RPMS does not. These shoulders are common phenomena in most ion trap mass spectrometers and their absence is indicative of an instrument malfunction or maladjustment. This phenomenon has also been observed on the standard PolarisQ when the electron multiplier (EM) is reaching the end of its life and is being operated at fairly high voltages (>2000V) (Figure 4). It is believed that in the RPMS, the spacing between the feedthrough for the dynode and the EM assembly was inadequate, and the dynode field $(10 \mathrm{kV})$ interacted unfavorably with the trajectory of the ions emitted by the analyzer, causing a non-linear response in the EM. In addition, the cabling for the dynode feedthrough may have experienced an insulation failure which caused fluctuations in the $10 \mathrm{kV}$ dynode potential.

Both of these possible failure modes have been addressed in modifications to the RPMS, which will be incorporated into the ITQ instrument configured for use by International Atomic Energy Agency (IAEA). 
Figure 3. Comparison Spectra of $\mathrm{UF}_{6}$ by RPMS and PolarisQ

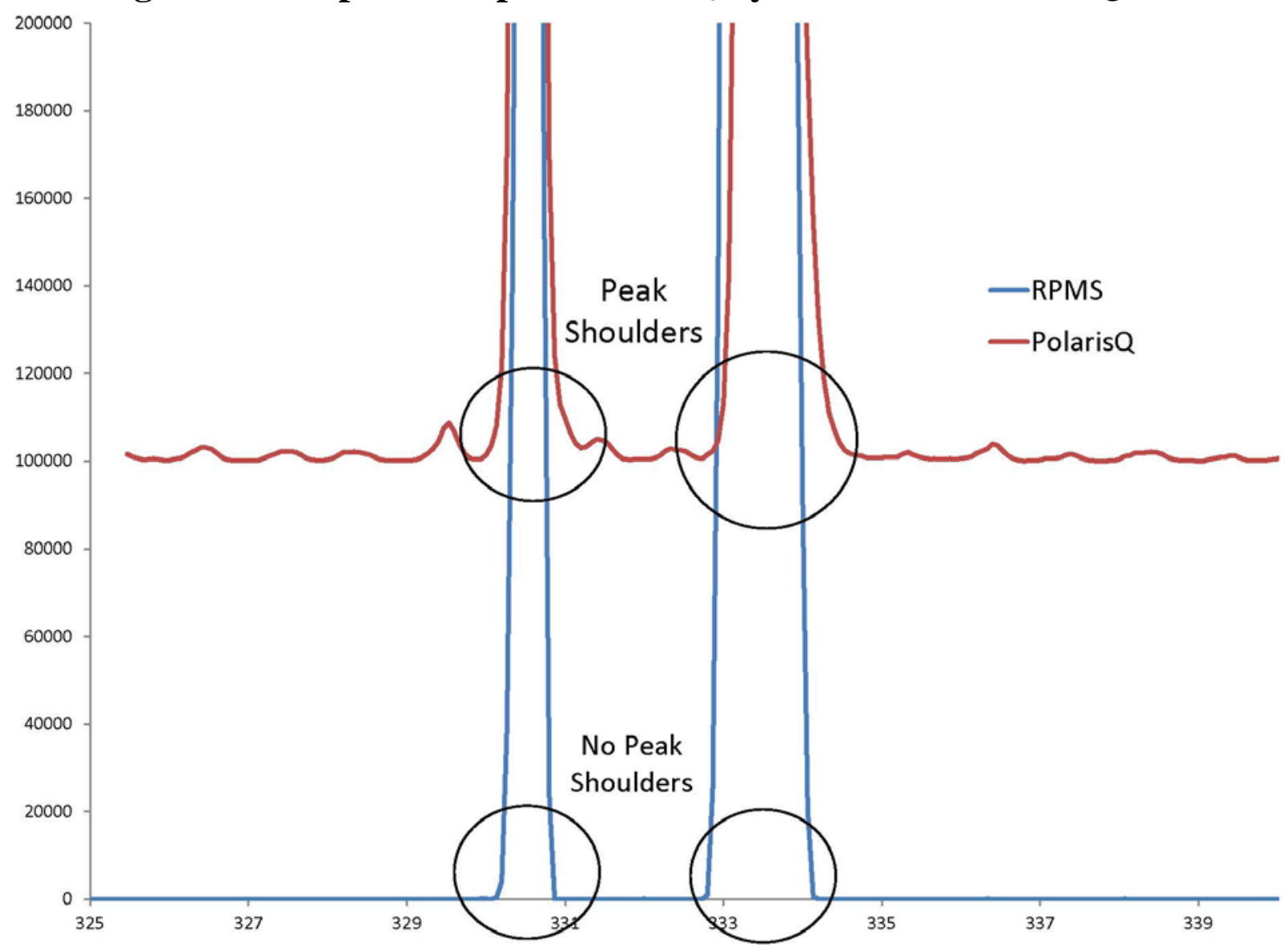




\section{Figure 4}

\section{PolarisQ Spectrum of $\mathrm{UF}_{6}$}

\section{High EM Voltage}

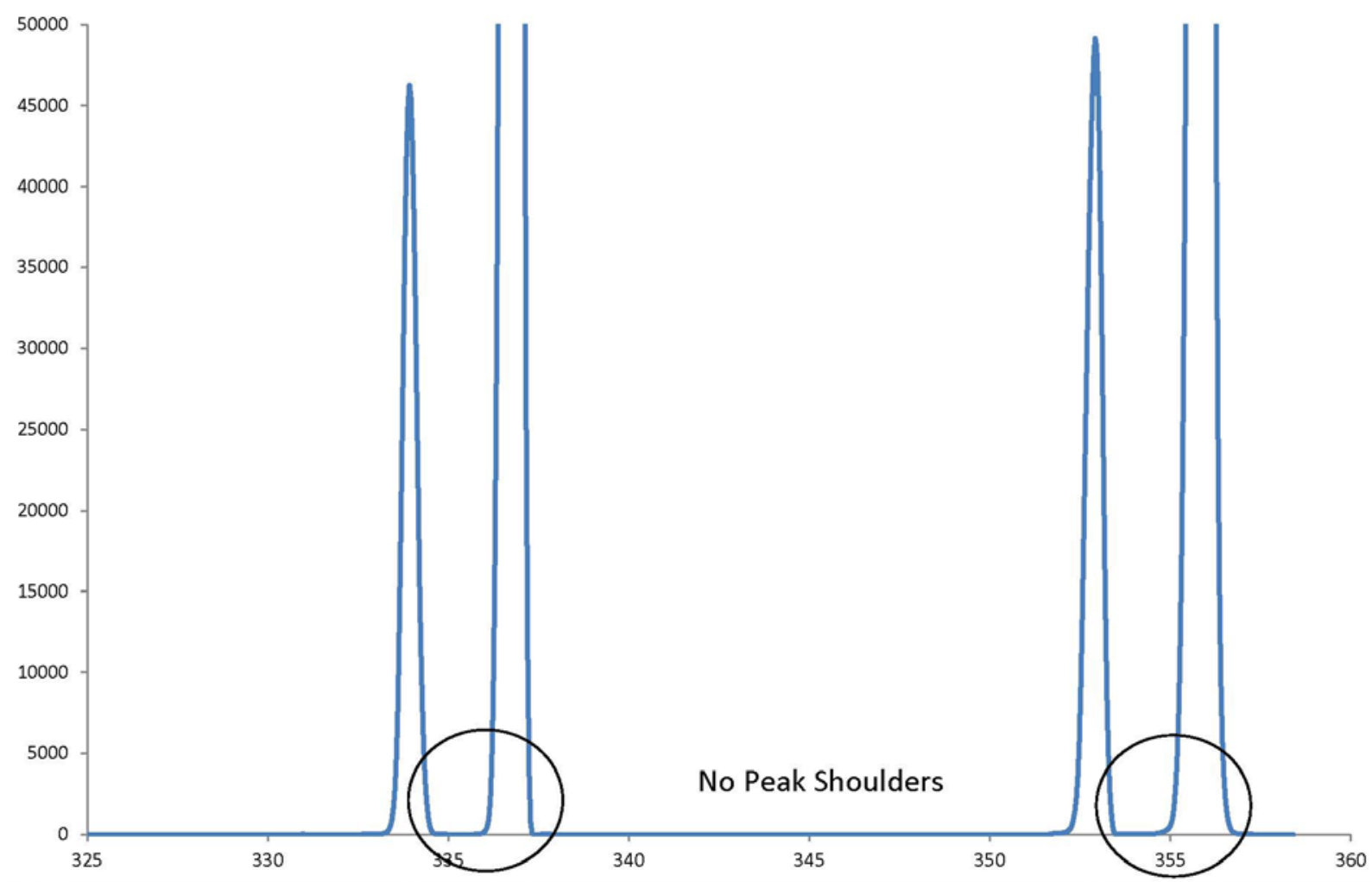

In addition to the testing performed with the RPMS at the ORNL test loop, a number of experiments were also performed with a standard PolarisQ to determine the precision of the mass spectrometer in measuring ${ }^{235} \mathrm{U} /{ }^{238} \mathrm{U}$ isotope ratios (Figure 5). The goal of IAEA, as communicated by their representatives during the September visit to ORNL, is to have a field deployable mass spectrometer which has a precision variability of less than $1 \%$ over one hour of measurement time. By optimizing sampling and mass spectrometric analysis conditions, precisions of $0.84 \%\left(\mathrm{UF}_{5}^{-}\right)$and $1.7 \%\left(\mathrm{UF}_{6}^{-}\right)$were achieved over an hour of sampling. However, some experimental conditions (sample flow rate/pressure, analyzer temperature, exposure of $\mathrm{EM}$ to $\mathrm{UF}_{6} / \mathrm{HF}$ ) could not be controlled as well as was desired. The goal of future experiments is to employ appropriate sampling and analysis equipment and conditions to closely control all the parameters identified in these experiments. With increased control, precision of less than $1 \%$ should be achievable. The investigators note that the performance of the standard PolarisQ is expected to be indicative of anticipated performance of the RPMS, as the fundamental instrument parameters are the same. Modifications to convert the ITQ instrument to the RPMS should only enhance instrument performance. 
Figure 5

\section{Mass Spectrum of Enriched $\mathrm{UF}_{6}$ by PolarisQ}

\section{9-28-15, Negative EI}

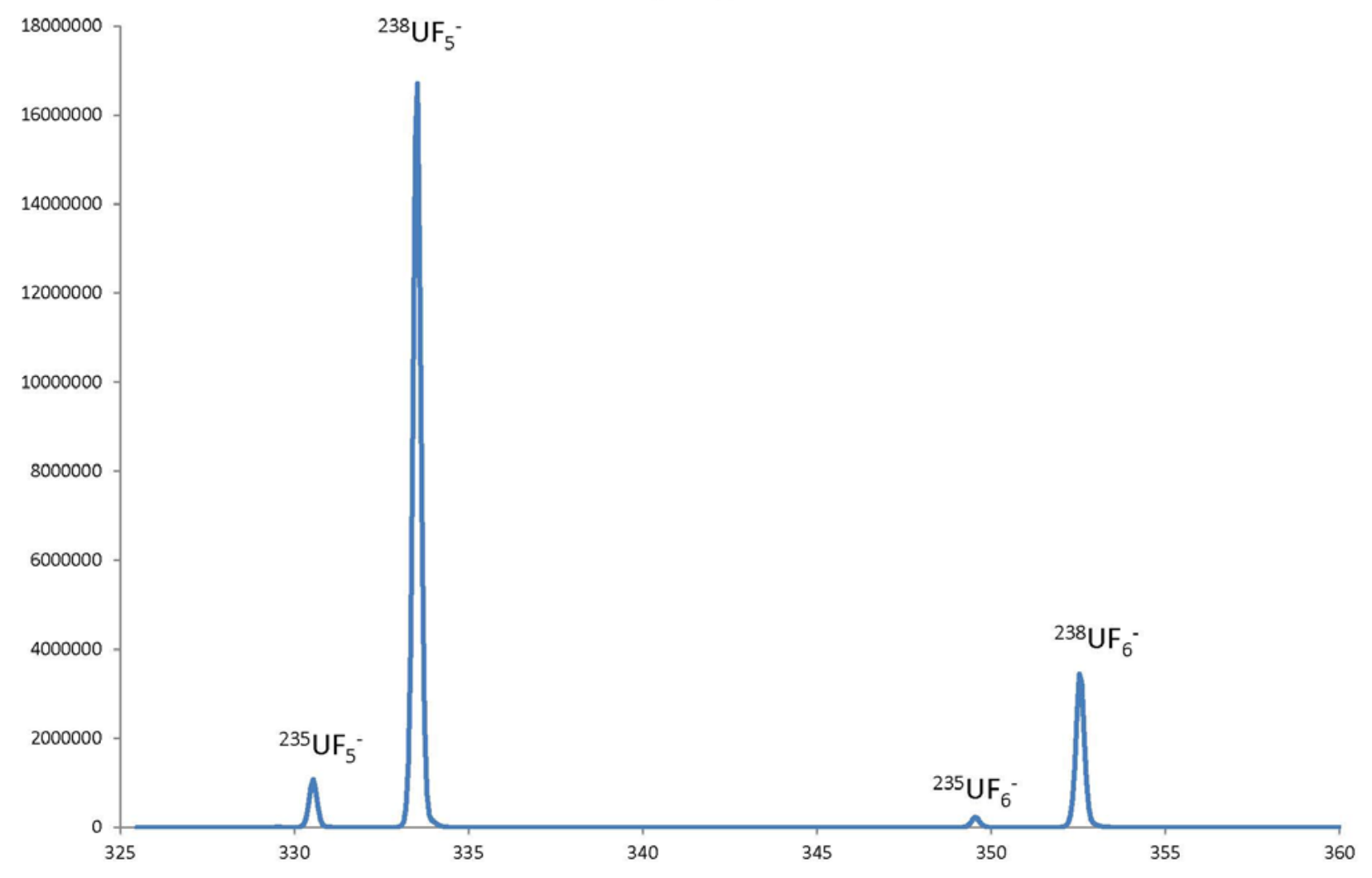

Acknowledgements

THIS TASK WAS SUPPORTED BY THE U.S. NATIONAL NUCLEAR SECURITY ADMINISTRATION (NNSA) OFFICE OF INTERNATIONAL NUCLEAR SAFEGUARDS (NA241), AND IT'S NEXT GENERATION SAFEGUARD 